Clinical Research Paper

\title{
Imatinib and polypharmacy in very old patients with chronic myeloid leukemia: effects on response rate, toxicity and outcome
}

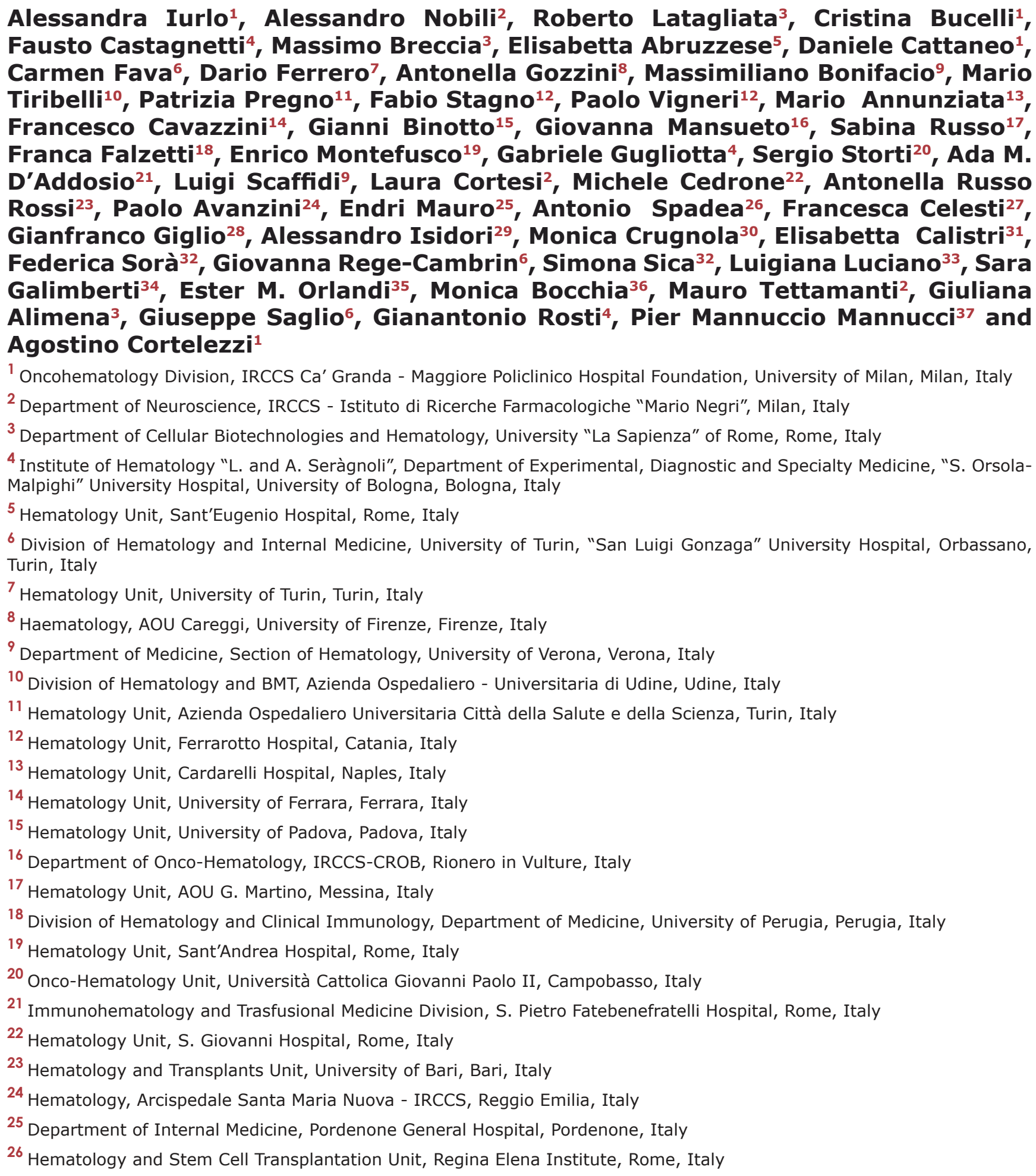




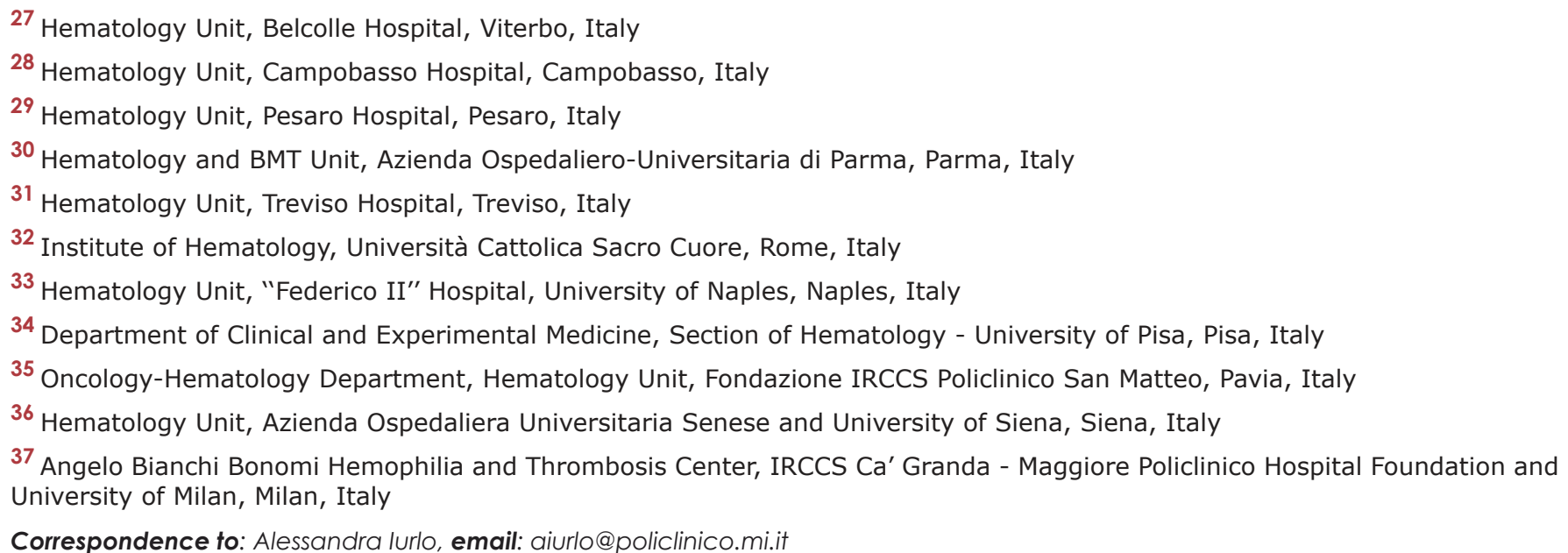

Correspondence to: Alessandra lurlo, email: aiurlo@policlinico.mi.it

Keywords: chronic myeloid leukemia; comorbidities; imatinib; old patients; polypharmacy

Received: June 07, $2016 \quad$ Accepted: July 13,2016 Published: August 27, 2016

\section{ABSTRACT}

Background: About $\mathbf{4 0 \%}$ of all patients with chronic myeloid leukemia are currently old or very old. They are effectively treated with imatinib, even though underrepresented in clinical studies. Furthermore, as it happens in the general population, they often receive multiple drugs for associated chronic illnesses. Aim of this study was to assess whether or not in imatinib-treated patients aged $>75$ years the exposure to polypharmacy ( 5 drugs or more) had an impact on cytogenetic and molecular response rates, event-free and overall survival, as well as on hematological or extra-hematological toxicity.

Methods: 296 patients at 35 Italian hematological institutions were evaluated.

Results: Polypharmacy was reported in 107 patients (36.1\%), and drugs more frequently used were antiplatelets, diuretics, proton pump inhibitors, ACE-inhibitors, beta-blockers, calcium channel blockers, angiotensin II receptors blockers, statins, oral hypoglycemic drugs and alpha blockers. Complete cytogenetic response was obtained in 174 patients $(58.8 \%), 78(26.4 \%)$ within 6 month, $63(21.3 \%)$ between 7 and 12 months. Major molecular response was obtained in 153 patients $(51.7 \%), 64(21.6 \%)$ within the 12 month. One hundred and twenty-eight cases $(43.2 \%)$ of hematological toxicity were recorded, together with 167 cases (56.4\%) of extra-hematological toxicity. Comparing patients exposed to polypharmacy to those without, no difference was observed pertaining to the dosage of imatinib, cytogenetic and molecular responses and hematological and extra-hematological toxicity.

Conclusion: Notwithstanding the several interactions reported in the literature between imatinib and some of the medications considered herewith, this fact does not seem to have a clinical impact on response rate and outcome.

\section{INTRODUCTION}

Chronic myeloid leukemia (CML) has an annual incidence of 1.1-1.8 cases per 100,000 adults, accounting for $15-20 \%$ of newly diagnosed cases of leukemia in adults [1]. The median age at diagnosis is $50-60$ years, with a peak at 70-74 years [2]. Thus, a significant proportion of CML patients are old or very old. In the past the primary aim of treatment in this subset of patients was to contain the leukemic mass, because older patients had no access to appropriate therapies like interferon or allogeneic bone marrow transplantation [3]. Patients' prognosis changed dramatically with the development of tyrosine kinase inhibitors (TKIs). This targeted approach has markedly increased the survival of CML patients, which is now approaching that of the general population $[1,4,5]$.

Even though a relevant proportion of CML patients are old or very old, they are generally underrepresented in clinical trials [2]. Moreover, older TKItreated patients suffer from comorbidities, whose number is usually higher in patients aged 75 years or more [6]. Several studies have established that multimorbidity is an 
Table 1: General characteristics of 296 chronic-phase CML patients, overall and according to the exposure or not to polypharmacy.

\begin{tabular}{|c|c|c|c|c|c|c|c|}
\hline Variables & $\begin{array}{l}\text { Overall cohort } \\
\text { (n. 296) }\end{array}$ & $\%$ & $\begin{array}{c}\text { No polypharmacy (A) } \\
\text { (N of drugs 0-4) } \\
\text { (n. 189) }\end{array}$ & $\%$ & $\begin{array}{c}\text { On polypharmacy } \\
\text { (B) } \\
(\mathrm{N} \text { of drugs }>5) \\
(\mathrm{n} .107)\end{array}$ & $\%$ & $\begin{array}{c}\text { A vs B } \\
p \text { value }\end{array}$ \\
\hline Male, n (\%) & 152 & 51.4 & 95 & 50.3 & 57 & 53.3 & 0.61 \\
\hline Mean age \pm SD & $79.4 \pm 3.7$ & & $79.0 \pm 3.6$ & & $80.1 \pm 3.7$ & & 0.01 \\
\hline \multicolumn{8}{|l|}{ Clinical parameters } \\
\hline \multicolumn{8}{|l|}{ Sokal score, n (\%) } \\
\hline Low & 4 & 1.4 & 3 & 1.6 & 1 & 0.9 & \multirow{4}{*}{0.83} \\
\hline Intermediate & 187 & 63.2 & 116 & 61.4 & 71 & 66.4 & \\
\hline High & 83 & 28.0 & 55 & 29.1 & 28 & 26.2 & \\
\hline Not available & 22 & 7.4 & 15 & 7.9 & 7 & 6.5 & \\
\hline \multicolumn{8}{|l|}{ Imatinib dosage, $\mathrm{n}(\%)$} \\
\hline$<400 \mathrm{mg} /$ day & 103 & 34.8 & 61 & 32.3 & 42 & 39.3 & \multirow{2}{*}{0.22} \\
\hline$>400 \mathrm{mg} /$ day & 193 & 65.2 & 128 & 67.7 & 65 & 60.7 & \\
\hline \multicolumn{8}{|l|}{ CCI, n (\%) } \\
\hline 0 & 105 & 35.5 & 79 & 41.8 & 26 & 24.3 & \multirow{3}{*}{0.004} \\
\hline 1 & 74 & 25.0 & 47 & 24.9 & 27 & 25.2 & \\
\hline $2+$ & 117 & 39.5 & 63 & 33.3 & 54 & 50.5 & \\
\hline \multicolumn{8}{|l|}{ Concomitant drugs } \\
\hline $\begin{array}{l}\text { Antihypertensives, } \\
\text { n (\%) }\end{array}$ & 214 & 72.3 & 117 & 61.9 & 97 & 90.7 & $<0.0001$ \\
\hline Diuretics, n (\%) & 123 & 41.6 & 51 & 27.0 & 72 & 67.3 & $<0.0001$ \\
\hline ACE inhibitors, $\mathrm{n}(\%)$ & 81 & 27.4 & 40 & 21.2 & 41 & 38.3 & 0.0015 \\
\hline Beta-blockers, n (\%) & 59 & 19.9 & 18 & 9.5 & 41 & 38.3 & $<0.0001$ \\
\hline $\begin{array}{l}\text { Calcium channel blockers, } \\
\text { n (\%) }\end{array}$ & 57 & 19.3 & 25 & 13.2 & 32 & 29.9 & 0.0005 \\
\hline $\begin{array}{l}\text { Angiotensin II receptor } \\
\text { blockers, } \mathrm{n}(\%)\end{array}$ & 55 & 18.6 & 24 & 12.7 & 31 & 29.0 & 0.0005 \\
\hline Alpha blockers, n (\%) & 27 & 9.1 & 9 & 4.8 & 18 & 16.8 & 0.0005 \\
\hline $\begin{array}{l}\text { Antiplatelet agents, } \\
\text { n (\%) }\end{array}$ & 144 & 48.6 & 70 & 37.0 & 74 & 69.2 & $<0.0001$ \\
\hline $\begin{array}{l}\text { Proton pump inhibitors, } n \\
(\%)\end{array}$ & 122 & 41.2 & 52 & 27.5 & 70 & 65.4 & $<0.0001$ \\
\hline Statins, n (\%) & 43 & 14.5 & 15 & 7.9 & 28 & 26.2 & $<0.0001$ \\
\hline $\begin{array}{l}\text { Oral hypoglycemic drugs, } \\
\mathrm{n}(\%)\end{array}$ & 40 & 13.5 & 18 & 9.5 & 22 & 20.6 & 0.007 \\
\hline \multicolumn{8}{|l|}{ Clinical outcomes } \\
\hline CCyR, n (\%) & 174 & 58.8 & 113 & 59.8 & 61 & 57.0 & 0.69 \\
\hline $\begin{array}{l}\text { CCyR within } 6 \text { months, } n \\
(\%)\end{array}$ & 78 & 26.4 & 49 & 25.9 & 29 & 27.1 & 0.57 \\
\hline $\begin{array}{l}\text { CCyR } 7 \text { to } 12 \text { months, } n \\
\text { (\%) }\end{array}$ & 63 & 21.3 & 42 & 22.2 & 21 & 19.6 & 0.80 \\
\hline MMR, n (\%) & 153 & 51.7 & 93 & 49.2 & 60 & 56.1 & 0.49 \\
\hline $\begin{array}{l}\text { Hematological toxicity, } n \\
(\%)\end{array}$ & 126 & 42.6 & 79 & 41.8 & 47 & 43.9 & 0.72 \\
\hline $\begin{array}{l}\text { Extra-hematological } \\
\text { toxicity, } \mathrm{n}(\%)\end{array}$ & 167 & 56.4 & 107 & 56.6 & 60 & 56.1 & 0.92 \\
\hline
\end{tabular}

Abbreviations: $\mathrm{SD}=$ standard deviation; $\mathrm{CCI}=$ Charlson Comorbidity Index; $\mathrm{CCyR}=$ Complete Cytogenetic Response; MMR=Major Molecular Response. 
independent predictor of all-cause mortality [7-9]: more specifically, a recent study by Saussele et al. [6] on the influence of comorbidities on the outcome of $1519 \mathrm{CML}$ patients found a strong negative association between comorbidities at diagnosis and overall survival (OS), even though comorbidities had no impact on treatment success. Furthermore, Efficace et al. [10] reported that comorbidities have a critical impact also on the healthrelated quality of life of these patients, particularly on general health, pain, physical functioning and vitality.

Due to multiple concomitant diseases, medication intake usually increases in older people, so that polypharmacy, a well-known risk factor for drug-drug interactions (DDIs) and adverse drug reactions (ADR), is highly prevalent. In older people, these risks are also increased because ageing is often accompanied by physiological changes in the pharmacokinetic (PK) and pharmacodynamic processes $[11,12]$. In older CML cases exposed to polypharmacy, the use of TKIs may be another risk factor for DDIs, because these drugs are extensively metabolized by cytochrome (CYP) P450.

In addition, some TKIs are substrates or inhibitors of the drug transporter P-glycoprotein $(\mathrm{PgP})$ and the organic cation transporter 1 (hOCT1). In particular, imatinib is metabolized primarily by the CYP 3A4 isoenzyme and is a substrate for hOCT1, PgP and breast cancer resistance protein (BCRP). The classes of drugs most commonly involved in DDIs with TKIs, and specifically with imatinib, are anticoagulants, proton pump inhibitors (PPI), antiplatelet agents, calcium channel blockers, statins, antiarrhythmic drugs, beta-blockers, digoxin, macrolides, azoles, rifampicin, dexamethasone and levothyroxine [13]. As a result of the effect of potential DDIs between concomitantly administered drugs, a standard regimen of TKIs may produce different levels of circulating and intracellular drug concentrations. Thus, a patient could on one hand have a low response to TKI due to subtherapeutic drug exposure or on the other hand develop TKI toxicity in case of overexposure. However, data specifically on concomitant medications in CML are not reported in the literature.

With this background, the aim of this study was to assess if in CML patients aged 75 years or more and imatinib-treated the exposure to polypharmacy had an impact on such main clinical outcomes as cytogenetic and molecular response rates, event-free survival (EFS) and OS, as well as on hematological or extra-hematological toxicity.

\section{RESULTS}

Two hundred and ninety-six very old patient with chronic-phase CML treated with imatinib were evaluated. Table 1 summarizes the characteristics of the whole cohort and of patients exposed to polypharmacy (5 or more drugs) compared with those not exposed to polypharmacy (less than 5 drugs).

In the overall cohort, mean age at diagnosis was 79.4 ( $\pm 3.7 \mathrm{SD})$ years, $152(51.4 \%)$ were males, $83(28 \%)$ were Sokal high risk and 103 (34.8\%) were treated with reduced dose imatinib $(<400 \mathrm{mg} /$ day $)$. Seventy-one patients $(24 \%)$ received other treatments before imatinib, mainly hydroxyurea (62 patients; $20.9 \%$ ) and/or interferon (9 patients; 3\%).

Polypharmacy was present in 107 patients (36.1\%), and the concomitant drugs more frequently used were antiplatelet agents taken by 152 patients (51.4\%), followed by diuretics and PPIs in 125 (42.3\%), ACE-inhibitors in $83(28 \%)$, beta-blockers in $61(20.6 \%)$, calcium channel blockers in $59(19.9 \%)$, angiotensin II receptor blockers (ARB) in 57 (19.3\%), statins in 44 (14.9\%), oral hypoglycemic drugs in $38(12.8 \%)$ and alpha blockers in $31(10.5 \%)$.

Complete cytogenetic response was obtained in 174 patients $(58.8 \%), 78(26.4 \%)$ within 6 month, 63 (21.3\%) between 7 and 12 months, and the remaining patients after 12 months. Major molecular response (MMR) was obtained in 153 patients $(51.7 \%)$, of whom $64(21.6 \%)$ within the $12^{\text {th }}$ month. However, differently from molecular analyses, a cytogenetic evaluation was not available in 58 patients (19.6\%). One hundred and twenty-eight cases $(43.2 \%)$ of hematological toxicity were recorded, together with 167 cases $(56.4 \%)$ of extrahematological toxicity.

Comparing patients exposed to polypharmacy with those without polypharmacy, a statistically significant difference between the two groups was observed for age and comorbidities. No difference was found in the two groups pertaining to the dosage of imatinib, cytogenetic and molecular responses and hematological and extrahematological toxicity (Table 1 ).

According to the starting dosage of imatinib, 193 patients $(65.2 \%)$ were treated with $400 \mathrm{mg} /$ day or more. The comparison of characteristics of patients treated with less than $400 \mathrm{mg} /$ day and those treated with $400 \mathrm{mg} /$ day or more showed a statistically significant difference only for age, concomitant use of antiplatelet and oral hypoglycemic agents, as well as for cytogenetic response by 12 months (Table 1S).

At multivariable logistic regression analysis (Table 2), polypharmacy was not associated at any time point with cytogenetic response, molecular response and hematological and extra-hematological toxicity. Furthermore, the exposure to polypharmacy failed to affect patient outcomes (EFS $p=0.79$; OS $p=0.74$ ) (Figure 1a and 1b), even though we confirmed the impact that comorbidities had on EFS $(p=0.001)$ or OS $(p<$ 0.001) (Figure 1S.a and 1S.b).

Finally, the exposure to multiple concomitant drugs (in particular, classes of antihypertensives, antiplatelet agents, PPIs, statins or oral hypoglycemic drugs) had no statistically significant effect on OS, EFS, cytogenetic 
Table 2: Response rate and toxicity of 296 chronic-phase CML patients aged 75 years or older according to the exposure or not to polypharmacy.

\begin{tabular}{|l|l|l|l|l|}
\hline Clinical outcomes & \multicolumn{2}{l|}{ Patients (n. 296) } \\
\hline & $\begin{array}{l}\text { No polypharmacy } \\
\text { (N of drugs 0-4) } \\
\text { (n. 192) }\end{array}$ & $\begin{array}{l}\text { Polypharmacy } \\
\text { (N of drugs >5) } \\
\text { (n. 104) }\end{array}$ & $\begin{array}{l}\text { Univariate } \\
\text { OR (95\% CI) }\end{array}$ & $\begin{array}{l}\text { Multivariable* } \\
\text { OR (95\% CI) }\end{array}$ \\
\hline CCyR within 6 months, n (\%) & $50(26)$ & $28(26.9)$ & $0.81(0.46-1.43)$ & $0.96(0.86-1.09)$ \\
\hline CCyR 7 to 12 months, n (\%) & $43(22.4)$ & $20(19.2)$ & $0.91(0.53-1.56)$ & $0.96(0.86-1.08)$ \\
\hline MMR, n (\%) & $93(48.4)$ & $60(57.7)$ & $0.84(0.51-1.38)$ & $1.00(0.90-1.11)$ \\
\hline Hematological toxicity, n (\%) & $80(41.7)$ & $46(44.2)$ & $0.93(0.57-1.52)$ & $1.03(0.93-1.14)$ \\
\hline Extra-hematological toxicity, n (\%) & $108(56.3)$ & $59(56.7)$ & $1.33(0.82-2.17)$ & $1.05(0.95-1.17)$ \\
\hline
\end{tabular}

Abbreviations: $\mathrm{OR}=$ Odds Ratio; $\mathrm{CCyR}=$ complete cytogenetic response; $\mathrm{MMR}=$ major molecular response.

* Adjusted for age and sex.
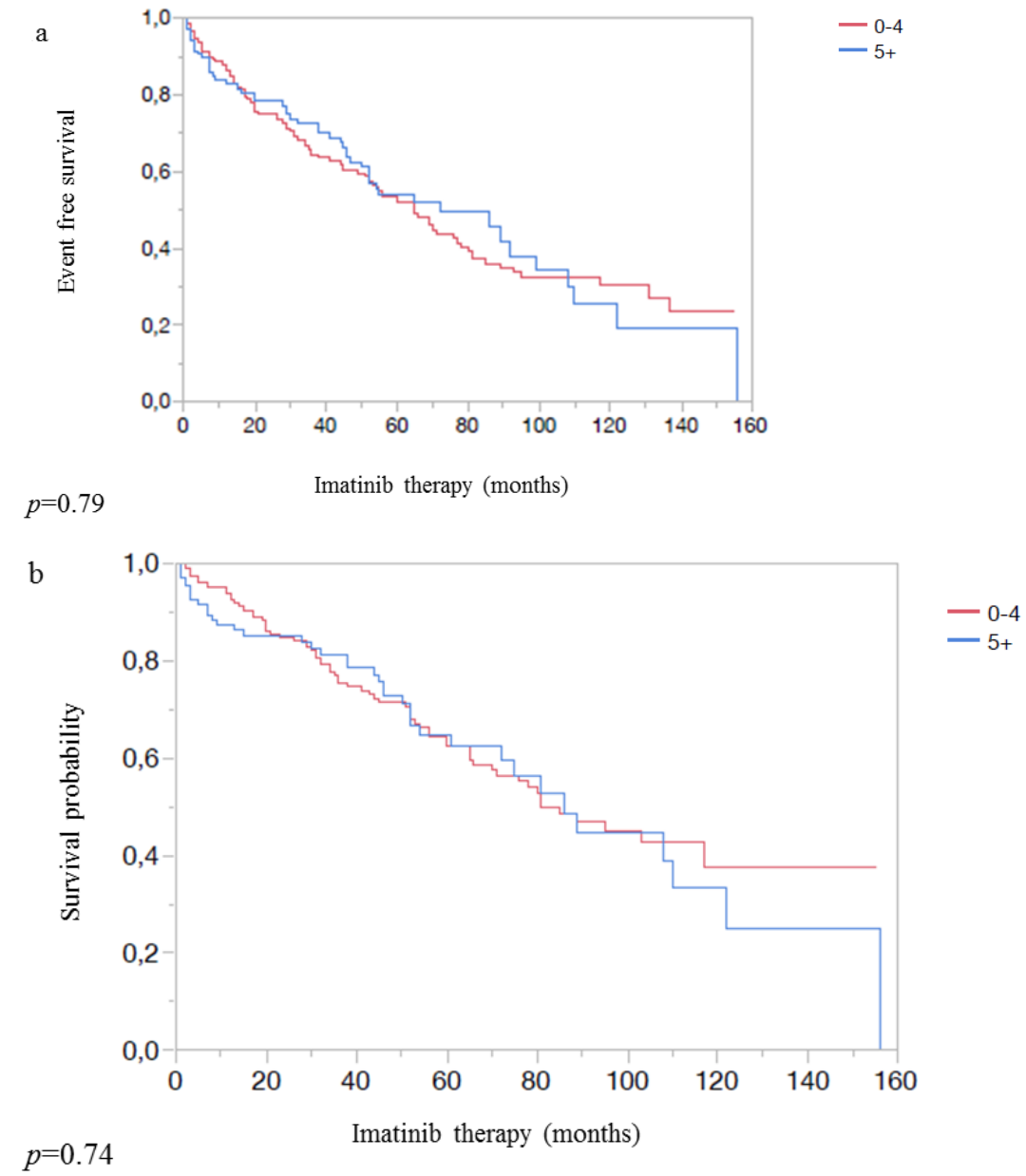

Figure 1: a. Event-free survival according to the exposure or not to polypharmacy. b. Overall survival according to the exposure or not to polypharmacy. 
response at any time-point, molecular response and hematological and extra-hematological toxicity (Table 2S).

\section{DISCUSSION}

Imatinib is a very effective treatment also for older CML patients in chronic phase, allowing high response rates and survival, comparable to those observed in the younger [14]. However, several older patients actually receive a starting dose of imatinib $<400 \mathrm{mg}$ /day, i.e. lower than the standard dose, owing to worse performance status compared to younger ones [15].

While the prognostic impact of comorbidities on CML has been previously studied, establishing their strong negative influence $[6,16]$, there are no data concerning the role that multiple drugs may have regarding response rate or outcome during imatinib therapy in very old CML patients. Indeed, there is a list of observed or potential DDIs between first and second generation TKIs (imatinib, dasatinib and nilotinib) and commonly used drugs which are concomitantly prescribed [13, 17], but this list is mainly the result of meta-analyses regarding in vitro studies rather than of in vivo studies. To address this issue, we retrospectively evaluated a large cohort of 296 patients from 35 Italian hematological centers aged 75 years or more at the time of imatinib start. Our data show that in $36.1 \%$ of these cases 5 or more concomitant drugs were regularly co-prescribed, and that diuretics, beta-blockers and statins were the most frequently used [18].

The achievement of CCyR at 6 and 12 months and of MMR were not influenced by the number and type of concomitant drugs. Similarly, the incidence and type of reported ADRs were not apparently influenced by the type and number of co-treatments. This is perhaps due to the variety of conditions in which combination therapies were analyzed, adding a level of treatment complexity owing to overlapping PK interactions (i.e. absorption, distribution, metabolism) [19]. Most importantly, at variance with comorbidities that did significantly influence patient outcome also in the present cohort, concomitant drugs and single classes of drugs failed to affect EFS or OS in old CML patients.

This is the first study which specifically considers the prognostic significance of TKIs and concomitant drug exposure in a large population of very old CML patients outside the context of a prospective clinical trial. However, we are aware that our study has some limitations: namely, its retrospective nature and the lack of information regarding the severity of the comorbidities, the latter due to the fact that they were evaluated by means of Charlson Comorbidity Index (CCI).

Notwithstanding the several PK interactions reported in the literature between imatinib and some of the medications considered herewith $[13,17]$, this does not seem to have a clinical impact on the response rate and outcome also in a real-life setting. Thus, we believe that an older age and a worse performance status are still fully compatible with TKIs use (and effectiveness), at variance with more aggressive cytotoxic treatments actually used in other hematological malignancies. Our findings may represent useful information for clinicians, allowing them to manage their very old CML patients in chronic phase in the best possible way. More specifically, it should be further considered that efficacy and safety of different co-prescribed drugs can be up- or downregulated by imatinib: for example, imatinib enhances the pharmacologic effects and possibly toxicity of cyclosporin, simvastatin, metoprolol, calcium channel blockers such as verapamil and diltiazem, amiodarone, and quinidine [13]. Therefore, in patients taking imatinib, these drugs should be either tapered or replaced by safer alternatives.

In conclusion, the prognosis of very old CML cases depended more on their comorbidities than on the number of drugs taken. Furthermore, a larger number of CML patients will have a life expectancy similar to that of general population, and this mainly due to TKIs treatment.

With this study we did underline the safety and efficacy of imatinib also in this subset of patients. It could be interesting to evaluate also the impact of second generation TKIs (dasatinib, nilotinib and bosutinib).

\section{MATERIALS AND METHODS}

\section{Patients}

In the frame of this observational study 35 Italian hematological centers were asked to retrospectively collect data on all CML patients on chronic phase admitted from January 2002 to October 2015, provided they were aged 75 years or more at the time of imatinib start.

\section{Methods}

All the following data were collected at baseline before imatinib initiation: sociodemographic and hematological variables, type and number of concomitant diseases and drugs and initial dose of imatinib. Any diagnosed clinical condition requiring a specific and chronic treatment was considered a concomitant disease and assessed as defined in the CCI [20]. Hematological and extra-hematological toxicities were graded according to the WHO scale, but for the purpose of this study only severe toxicities were considered in the analysis.

We defined polypharmacy according to the REPOSI registry as exposure of a CML patient to five or more different medications in addition to imatinib [21]. In particular, we analyzed the effects of drugs that may have a potential risk of interaction with imatinib, such as antihypertensives, ACE-inhibitors, beta-blockers, calcium channel blockers, ARB, antiplatelet agents, PPI, statins 
and oral hypoglycemic drugs [13].

Monitoring and responses followed the current European LeukemiaNet recommendations [22-24].

Overall survival was calculated from the date of imatinib start until death due to any cause. Event-free survival was calculated from the date of imatinib start to any of the following events: primary hematological resistance to imatinib, definitive imatinib discontinuation due to toxicity or any other cause, secondary hematological or cytogenetic resistance to imatinib or death due to any cause.

\section{Statistical analysis}

Clinical and sociodemographic characteristics of the sample were described using absolute numbers and percentages, except that for age mean and standard deviation (SD) were used. Comparison between subgroups with and without polypharmacy, or with dosage of imatinib lower/higher than $400 \mathrm{mg} /$ day were performed by means of chi square test for all variables except for age, where a $t$-test was used. The univariable association between polypharmacy and CCyR (0 to 6 months, 7 to 12 months, more than 12 months) was studied using an ordinal logistic regression model and reporting odds ratios (ORs) and 95\% confidence intervals (CIs). The associations between polypharmacy and molecular response (MR), hematological or extra-hematological toxicity were studied using nominal logistic regression models and reporting ORs and 95\% CIs. Multivariable ordinal/nominal logistic regressions for all models were performed correcting for age and sex. Kaplan-Meier curves were plotted to analyze differences in survival from the beginning of imatinib therapy to the occurrence of OS or EFS by presence of polypharmacy, testing differences by means of log-rank tests. Cox proportional hazards models were used to obtain the hazard ratios (HRs) of OS or EFS for polypharmacy in a multivariable models (adjusting for age and sex). Single drug class associations with CCyR, MR, toxicity, OS or EFS were analyzed as reported above for polypharmacy. Categorized age was used in multivariable models to correct for imbalances. Statistical analyses were performed using JMP Pro 12.1 (SAS Institute Inc.).

\section{CONFLICTS OF INTEREST}

A. Iurlo has received honoraria from Novartis, Bristol Myers Squibb (BMS), Pfizer, ARIAD and SHIRE. R. Latagliata has received honoraria from Novartis, BMS, Celgene, and SHIRE. F. Castagnetti has acted as a consultant for and received honoraria from Novartis, BMS, Pfizer and ARIAD. M. Breccia has acted as a consultant for BMS, Novartis, Pfizer and ARIAD. E.
Abruzzese and E. Montefusco have received consulting fees and honoraria from Novartis and BMS. A. Gozzini, C. Fava, and G. Rege-Cambrin have received honoraria from Novartis and BMS. D. Ferrero has received financial support from Novartis and BMS. G. Gugliotta has acted as a consultant and received honoraria from Novartis and BMS. F. Cavazzini and M. Cedrone have received honoraria and payment for speakers bureaus from BMS and Novartis. G. Saglio has acted as a consultant for and received honoraria from BMS, Novartis, ARIAD and Celgene. G. Rosti has acted as a consultant for Novartis, BMS and ARIAD and served on the speakers' bureaus of Novartis, BMS and Roche. No other conflicts of interest were declared.

\section{FUNDING}

The only funds used were provided by the authors' institutions.

\section{REFERENCES}

1. Jemal A, Siegel R, Xu J, Ward E. Cancer statistics, 2010. CA Cancer J Clin. 2010; 60: 277-300.

2. Hoffmann VS, Baccarani M, Hasford J, Lindoerfer D, Burgstaller S, Sertic D, Costeas P, Mayer J, Indrak K, Everaus H, Koskenvesa P, Guilhot J, Schubert-Fritschle $\mathrm{G}$, et al. The EUTOS population-based registry: incidence and clinical characteristics of 2904 CML patients in 20 European Countries. Leukemia. 2015; 29: 1336-1343.

3. Silver RT, Woolf SH, Hehlmann R, Appelbaum FR, Anderson J, Bennett C, Goldman JM, Guilhot F, Kantarjian HM, Lichtin AE, Talpaz M, Tura S. An evidence-based analysis of the effect of busulfan, hydroxyurea, interferon, and allogeneic bone marrow transplantation in treating the chronic phase of chronic myeloid leukemia: developed for the American Society of Hematology. Blood. 1999; 94: 1517-1536.

4. Okuda K, Matulonis U, Salgia R. Factor independence of human myeloid leukemia cell lines is associated with increased phosphorylation of the proto-oncogene Raf-1. Exp Hematol. 1994; 22: 1111-1117.

5. Raitano AB, Halpern JR, Hambuch TM. The Bcr-Abl leukemia oncogene activates Jun kinase and requires Jun for transformation. Proc Natl Acad Sci USA. 1995; 92: 1174611750 .

6. Saussele S, Krauss MP, Hehlmann R, Lauseker M, Proetel U, Kalmanti L, Hanfstein B, Fabarius A, Kraemer D, Berdel WE, Bentz M, Staib P, de Wit M, et al. Impact of comorbidities on overall survival in patients with chronic myeloid leukemia: results of the randomized CML study IV. Blood. 2015; 126: 42-49.

7. Xhaard A, Porcher R, Chien JW, de Latour RP, Robin M, Ribaud P, Rocha V, Devergie A, Ferry C, Martin PJ, Socié 
G. Impact of comorbidity indexes on non-relapse mortality. Leukemia. 2008; 22: 2062-2069.

8. Smith AW, Reeve BB, Bellizzi KM, Harlan LC, Klabunde $\mathrm{CN}$, Amsellem M, Bierman AS, Hays RD. Cancer, comorbidities, and health-related quality of life of older adults. Health Care Financ Rev. 2008; 29: 41-56.

9. Castagnetti F, Gugliotta G, Breccia M, Stagno F, Iurlo A, Albano F, Abruzzese E, Martino B, Levato L, Intermesoli T, Pregno P, Rossi G, Gherlinzoni F, et al. Long-term outcome of chronic myeloid leukemia patients treated frontline with imatinib. Leukemia. 2015; 29: 1823-1831.

10. Efficace F, Rosti G, Breccia M, Cottone F, Giesinger JM, Stagno F, Iurlo A, Russo Rossi A, Luciano L, Martino B, Galimberti S, Turri D, Bergamaschi M, et al. The impact of comorbidity on health-related quality of life in elderly patients with chronic myeloid leukemia. Ann Hematol. 2016; 95: 211-219.

11. Steinman MA, Hanlon JT. Managing medications in clinically complex elders: "There's got to be a happy medium". JAMA. 2010; 304: 1592-1601.

12. Veehof LJG, Meyboom-de Jong B, Haaijer-Rasamp FM. Polypharmacy in the elderly - a literature review. Eur J Gen Pract. 2000; 6: 98-106.

13. Haouala A, Widmer N, Duchosal MA, Montemurro M, Buclin T, Decosterd LA. Drug interactions with the tyrosine kinase inhibitors imatinib, dasatinib, and nilotinib. Blood. 2011; 117: e75-87.

14. Gugliotta G, Castagnetti F, Palandri F, Breccia M, Intermesoli T, Capucci A, Martino B, Pregno P, Rupoli S, Ferrero D, Gherlinzoni F, Montefusco E, Bocchia M, et al. Frontline imatinib treatment of chronic myeloid leukemia: no impact of age on outcome, a survey by the GIMEMA CML Working Party. Blood. 2011; 117: 5591-5599.

15. Latagliata R, Ferrero D, Iurlo A, Cavazzini F, Castagnetti F, Abruzzese E, Fava C, Breccia M, Annunziata M, Stagno F, Tiribelli M, Binotto G, Mansueto G, Gozzini A, Russo S, Cavalli L, Mansueto G, et al. Imatinib in very elderly patients with chronic myeloid leukemia in chronic phase: a retrospective study. Drugs Aging. 2013; 30: 629-637.

16. Breccia M, Luciano L, Latagliata R, Castagnetti F, Ferrero D, Cavazzini F, Trawinska MM, Annunziata M, Stagno F, Tiribelli M, Binotto $G$, Crisà $E$, Musto $P$, et al. Age influences initial dose and compliance to imatinib in chronic myeloid leukemia elderly patients but concomitant comorbidities appear to influence overall and event-free survival. Leuk Res. 2014; 38: 1173-1176.
17. van Leeuwen RW, van Gelder T, Mathijssen RH, Jansman FG. Drug-drug interactions with tyrosine-kinase inhibitors: a clinical perspective. Lancet Oncol. 2014; 15: e315-326.

18. Gu Q, Dillon CF, Burt VL. Prescription drug use continues to increase: U.S. prescription drug data for 2007-2008. NCHS Data Brief. 2010; (42): 1-8.

19. Balducci L, Dolan D. Chronic Myelogenous Leukemia (CML) in the elderly. Mediterr J Hematol Infect Dis. 2014; 6: e2014037.

20. Charlson ME, Pompei P, Ales KL, MacKenzie CR. A new method of classifying prognostic comorbidity in longitudinal studies: development and validation. J Chronic Dis. 1987; 40: 373-383.

21. Nobili A, Licata G, Salerno F, Pasina L, Tettamanti M, Franchi C, De Vittorio L, Marengoni A, Corrao S, Iorio A, Marcucci M, Mannucci PM; SIMI Investigators. Polypharmacy, length of hospital stay, and in-hospital mortality among elderly patients in internal medicine wards. The REPOSI study. Eur J Clin Pharmacol. 2011; 67: 507519.

22. Baccarani M, Saglio G, Goldman J, Hochhaus A, Simonsson B, Appelbaum F, Apperley J, Cervantes F, Cortes J, Deininger M, Gratwohl A, Guilhot F, Horowitz $\mathrm{M}$, et al. Evolving concepts in the management of chronic myeloid leukemia: recommendations from an expert panel on behalf of the European LeukemiaNet. Blood. 2006; 108: 1809-1820.

23. Baccarani M, Cortes J, Pane F, Niederwieser D, Saglio G, Apperley J, Cervantes F, Deininger M, Gratwohl A, Guilhot F, Hochhaus A, Horowitz M, Hughes T, et al. Chronic myeloid leukemia: an update of concepts and management recommendations of European LeukemiaNet. J Clin Oncol. 2009; 27: 6041-6051.

24. Baccarani M, Deininger MW, Rosti G, Hochhaus A, Soverini S, Apperley JF, Cervantes F, Clark RE, Cortes JE, Guilhot F, Hjorth-Hansen H, Hughes TP, Kantarjian HM, et al. European LeukemiaNet recommendations for the management of chronic myeloid leukemia: 2013. Blood. 2013; 122: 872-884. 